3D indium tin oxide electrodes by ultrasonic spray deposition for current collection applications

Peer-reviewed author version

VAN DEN HAM, Jonathan; ELEN, Ken; BONNEUX, Gilles; MAINO, Giulia; Notten, P. H. L.; VAN BAEL, Marlies \& HARDY, An (2017) 3D indium tin oxide electrodes by ultrasonic spray deposition for current collection applications. In: JOURNAL OF POWER SOURCES, 348, p. 130-137.

DOI: 10.1016/j.jpowsour.2017.03.006

Handle: http://hdl.handle.net/1942/24191 


\title{
3D indium tin oxide electrodes by ultrasonic spray deposition for current collection applications
}

\author{
E.J. van den Ham ${ }^{a}$, K. Elen ${ }^{a, b}$, G. Bonneux ${ }^{a}$, G. Maino ${ }^{a}$, P.H.L. Notten ${ }^{c, d}$, M.K. Van Bael ${ }^{a}$ and A. Hardy ${ }^{a}$
}

Keywords: ITO, films, , current collector, 3D structures, TCO, transparent conductive oxide

\begin{abstract}
${ }^{a}$ UHasselt, Hasselt University, Institute for Materials Research, Inorganic and Physical Chemistry and imec - division imomec, Martelarenlaan 42, 3500 Hasselt, Belgium.

${ }^{\mathrm{b}}$ imec vzw, division imomec, Wetenschapspark 1, B-3590 Diepenbeek, Belgium

${ }^{\mathrm{c}}$ Eindhoven University of Technology, P.O. Box 513, 5600 MB Eindhoven, The Netherlands

${ }^{d}$ Forschungszentrum Jülich, Fundamental Electrochemistry (IEK-9), D-52425, Jülich, Germany
\end{abstract}

\section{Abstract}

Three dimensionally (3D) structured indium tin oxide (ITO) thin films are synthesized and characterized as a 3D electrode material for current collection applications. Using metal citrate chemistry in combination with ultrasonic spray deposition, a low cost wet-chemical method has been developed to achieve conformal ITO coatings on non-planar scaffolds. Although there is room for improvement with respect to the resistivity $\left(9.9 \cdot 10^{-3} \Omega \cdot \mathrm{cm}, 220 \mathrm{~nm}\right.$ thick planar films), high quality 3D structured coatings were shown to exhibit conductive properties based on ferrocene reactivity. In view of applications in Li-ion batteries, the electrochemical stability of the current collector was investigated, indicating that stability is guaranteed for voltages of $1.5 \mathrm{~V}$ and up (vs. $\mathrm{Li}^{+} / \mathrm{Li}$ ). In addition, subsequent 3D coating of the ITO with $\mathrm{WO}_{3}$ as a negative electrode (battery) material confirmed the 3D ITO layer functions as a proper current collector. Using this approach, an over 4-fold capacity increase was booked for 3D structured $\mathrm{WO}_{3}$ in comparison to planar samples, confirming the current collecting capabilities of the 3D ITO coating. Therefore, the 3D ITO presented is considered as a highly interesting material for 3D battery applications and beyond. 


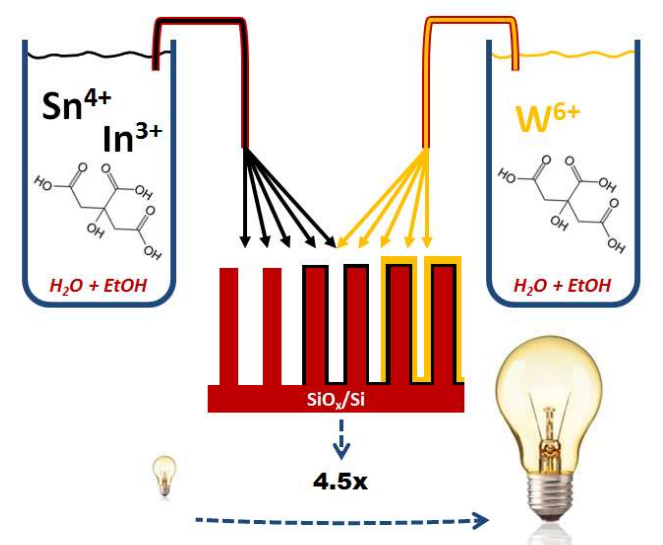

\section{Introduction}

In a world seeking a sustainable future, smart materials and structures are opted for energy harvesting, storage and consuming applications. 3D structure enhancements are often applied to enhance active material performance, mostly based on a kinetic advantage due to a better current distribution per (active) material volume. Examples of this technology can be found within the field of hydrogen technology [1], 3D supercapacitors [2], PV applications [3], 3D lighting (LEDs) [4,5] and battery technology $[6,7]$. For 3D LED applications, based on the enlargement of active surface area for light generation, 3D structured transparent conductive oxides (TCO's) can contribute to highly efficient 3D LEDs [4]. Upon successful implementation of such a 3D electrode, further improvement of these devices would be possible as these systems currently lack a transparent, 3D structured electrode as top contact for the GaN pillar structures [5]. For 3D Li-ion batteries, or more specifically '3D integrated all-solid-state Li-ion batteries' [7,8], 3D structured electrodes (or also referred to as 'current-collectors' in this field) are essential for transportation of electrons to the active battery materials. 3D all-solid-state Li-ion batteries combine the benefits of an all-solid state battery, namely increased lifetime, enhanced safety and miniaturization - with a significant improvement in capacity due to 3D architectures $[6,7,9]$. As all these applications involve the exchange of electrons; suitable electrode materials are required, acting as current collectors for 3D structured (energy) materials. Although several examples of 3D structured metals and doped semi-conductors are available [10- 
E.J. van den Ham et al. - Published in Journal of Power Sources 348: 130-137 (30 April 2017)

12], conductive coatings resistant to high temperatures are rare. Various reports have been made for 3D metallic foams, consisting of porous (metallic) $\mathrm{Cu}$ or Ni. Although corrosion of these metals can be utilized to form active battery materials directly on the current collector $[13,14]$, both structure and required synthesis temperature of (ceramic) electrode materials such as $\mathrm{Li}_{4} \mathrm{Ti}_{5} \mathrm{O}_{12}$ and $\mathrm{LiCoO}_{2}$ render this approach unsuitable for 3D thin film all-solid-state Li-ion batteries $[11,15,16]$. Currently, the choice of 3D structured thin film current collectors is primarily limited to ALD grown titanium nitride (TiN) $[17,18]$ and platinum (Pt) $[19,20]$. More specifically, TiN is an excellent choice as a current collecting electrode for 3D Li-ion battery applications, as the material acts as a current collector and buffer layer to prevent lithium diffusion into the 3D structured support [18]. Although both TiN and Pt exhibit superior conductivity, the vacuum conditions of the costly deposition method limits upscaling possibilities. Moreover, $\mathrm{TiN}$ tends to oxidize and forms poorly conducting $\mathrm{TiO}_{2}$ under oxidative annealing conditions [21]. Hence, emerging 3D structured technologies requiring elevated annealing temperatures are limited by the lack of choice of suitable 3D structured electrode materials [22]. Besides metals and nitrides, Transparent Conductive Oxides (TCOs) are also considered as current collectors for various applications. Using ALD, conformal coatings of aluminium doped zinc oxide (AZO) and indium tin oxide (ITO) have been reported [23,24]. However, as stated previously, ALD is a costly route. Via chemical bath deposition, zinc oxide $(\mathrm{ZnO})$ was deposited in trenches, though the aspect ratios achieved were below unity [25]. Within this study, the deposition and function of ITO as an electrode material for current collecting applications is investigated by using a wet-chemical route with a huge upscaling potential. Being an oxide, concessions have to be made with respect to the resistivity, while comparing this material with metallic conductors. Needless to say, the crystallinity and occurrence of vacancies is influenced by annealing, hence the conductivity of ITO is susceptible to (high temperature) annealing conditions dictated by a second material in case stacking is attempted (in view of device integration). However, oxidation issues (a major issue for the TiN previously mentioned) cannot occur as the ions involved are already in the highest oxidation state $\left(\mathrm{In}^{3+}\right.$ and $\left.\mathrm{Sn}^{4+}\right)$. Therefore, the 3D structured ITO films are an interesting 
E.J. van den Ham et al. - Published in Journal of Power Sources 348: 130-137 (30 April 2017)

candidate to serve as potentially high temperature resistant current collectors for (3D) thin film Li-ion batteries.

Recently, Gielis et al. developed a process to deposit oxide materials on non-planar surfaces with high aspect ratios, using a tailored wet-chemical approach in combination with ultrasonic spray deposition $[22,26]$. In this approach, a stable (metal-citrate) precursor is atomized via vibrations at ultrasonic frequency, yielding a fixed droplet size distribution, where the average size of the droplets leaving the nozzle is approximately $8 \mu \mathrm{m}$ [27]. Due to evaporation, the droplets are even smaller when they hit the substrate [28]. This possibly enables the deposition of 3D structured TCO materials, to act as current collecting electrodes in various applications. In this study, the current collecting capabilities of ITO were studied in view of application in 3D Li-ion batteries. In addition, the ITO was coated with a negative electrode material for Li-ion batteries as a proof-of-principle. $\mathrm{WO}_{3}$ was chosen for this purpose, because of (i) the relatively high volumetric energy density and stable cycling behavior $\left(640 \mathrm{mAh} \cdot \mathrm{cm}^{-3}\right)$ [29], (ii) the compatibility with relatively unstable solid electrolytes, such as Perovskite $\mathrm{Li}_{0.35} \mathrm{La}_{0.55} \mathrm{TiO}_{3}[29]$ and (iii) the possibility to deposit this material on 3D scaffolds by ultrasonic spray deposition [22].

\section{Experimental}

An aqueous citrato peroxo $\mathrm{Sn}^{4+}$ solution was prepared according to the synthesis route developed by Stanulis et al. [30]. Hydrogen peroxide $\left(\mathrm{H}_{2} \mathrm{O}_{2}\right.$, Acros Organics, 35\%) was added to tin oxalate (Sigma Aldrich, $98 \%$ ) in a $12: 1$ molar ratio and heated to $80^{\circ} \mathrm{C}$. Next, citric acid (CA, Sigma Aldrich, $\geq 99 \%$ ) was added in a $6: 1$ molar ratio with respect to $\mathrm{Sn}$ and heated to $80^{\circ} \mathrm{C}$. Finally, the $\mathrm{pH}$ was raised to 7.0 with ammonia $\left(\mathrm{NH}_{3}\right.$, Merck, $\left.32 \%\right)$ to obtain the aqueous $\mathrm{Sn}^{4+}$ precursor, with a colorless, transparent appearance. $\operatorname{In}^{3+}$ citrate was prepared by mixing indium hydroxide $\left(\ln (\mathrm{OH})_{3}\right.$, Umicore electro-optic materials) and CA in a 1:4 molar ratio, followed by the addition of water. This mixture was heated under reflux conditions for 90 minutes at $120^{\circ} \mathrm{C}$. After cooling, the $\mathrm{pH}$ was 
E.J. van den Ham et al. - Published in Journal of Power Sources 348: 130-137 (30 April 2017)

adjusted to 7.0 with ammonia, yielding a transparent colorless solution. For both $\mathrm{Sn}^{4+}$ - and $\mathrm{In}^{3+}$ solutions, the excess of CA was required to prevent precipitations. The concentrations of both precursors were determined by inductively coupled plasma-atomic emission spectroscopy (ICP-AES, Optima 3300, PerkinElmer). Next, the aqueous $\mathrm{Sn}^{4+}$ - and $\mathrm{In}^{3+}$-solutions were mixed in a 1:9 molar ratio. Finally, ethanol was added to the aqueous precursor in a 9:10 volumetric ratio, as proposed by Gielis et al. [22,26]. The total metal-ion concentration of the final mixed precursor amounted to 10 $\mathrm{mM}$.

Three different types of substrates were used for this study: (i) planar Si wafers with $200 \mathrm{~nm}$ thermal oxide (imec, Heverlee, Belgium), (ii) planar Si wafers with 1-2 nm native oxide (imec, Heverlee, Belgium), (iii) Si micro-cylinders of $50 \mu \mathrm{m}$ in length, $1.5 \mu \mathrm{m}$ radius with an inter-cylinder distance of 5 $\mu \mathrm{m}$, prepared by reactive ion etching (imec, Belgium), further referred to as 'Si micro-cylinders' and (iv) trench structured Si wafers, prepared by reactive ion etching (Philips, Eindhoven, the Netherlands) further referred to as 'trenches'. All the substrates were submitted to a cleaning procedure, either by applying a UV/O ${ }_{3}$ treatment $\left(30\right.$ minutes at $60^{\circ} \mathrm{C}$ ) or a modified piranha cleaning procedure. The latter consisted of a consecutive sulphuric acid-peroxide and ammonia-peroxide (SPM/APM) treatment [31]. Tungsten oxide was deposited consecutively on top of the ITO coated substrates, as reported earlier [22].

The mixed precursor was deposited on various substrates via ultrasonic spray deposition (Exacta Coat, Sono-Tek cooperation) with set deposition temperatures ranging from $170^{\circ} \mathrm{C}$ to $230^{\circ} \mathrm{C}$. The liquid was dispensed at $0.2 \mathrm{ml} \cdot \mathrm{min}^{-1}$ and the $\mathrm{N}_{2}$ carrier gas pressure was set at $1.5 \mathrm{psi}$. The distance of the spray nozzle to the substrate was approximately $2.7 \mathrm{~cm}$ and it moved with a speed of $100 \mathrm{~mm} \cdot \mathrm{s}^{-1}$. The number of deposition cycles (i.e. the number of times the spray head passes a point on the substrate) was varied from 10 to 50 times with waiting times of 5 seconds between the deposition cycles. For 2D samples, intermediate heat treatments were applied every 5 cycles. On 3D microcylinders and trench structures no intermediate annealing was applied. Heat treatments were done 
E.J. van den Ham et al. - Published in Journal of Power Sources 348: 130-137 (30 April 2017)

on hot plates $\left(300^{\circ} \mathrm{C}\right.$ and $\left.600^{\circ} \mathrm{C}\right)$ for 2 minutes. The post deposition anneal was performed using a rapid thermal processing unit (Annealsys, AS-one) at $800^{\circ} \mathrm{C}$ in dry air $\left(1 \mathrm{ml} \cdot \mathrm{min}^{-1}\right)$ for 10 minutes, followed by 3 hours at $400^{\circ} \mathrm{C}$ in nitrogen $\left(1 \mathrm{ml} \cdot \mathrm{min}^{-1}\right)$. In both cases, the heating rate was $10^{\circ} \mathrm{C} \cdot \mathrm{s}^{-1}$. This annealing procedure was adopted from Sugahara et al. [32]. Tungsten oxide was deposited consecutively on top of the ITO coated substrates, as reported earlier [22].

The thermal decomposition profile of the dried ITO-precursor gel, obtained by drying the precursor solution at $60^{\circ} \mathrm{C}$, was investigated by thermogravimetric analysis (TGA, TA instruments Q500). $2 \mathrm{mg}$ of the gel was heated at $10^{\circ} \mathrm{C} \cdot \mathrm{min}^{-1}$ using dry air $\left(0.1 \mathrm{~L} \cdot \mathrm{min}^{-1}\right)$ in a platinum crucible. The morphology of the annealed ITO films was investigated via scanning electron microscopy (SEM, FEI Quanta 200F). Profilometry was done with Bruker Dektak 150 Surface Profiler, with a $2 \mu \mathrm{m}$ tip with a measurement length of $10 \mathrm{~mm}$. The crystallization of the films was investigated by XRD on a Bruker D8 equipped with a line-scan detector (Lynx eye), using a step size of $0.040^{\circ}$ and a counting time of 0.3 seconds per step at room temperature. Van der Pauw measurements (Keithley 2400 SourceMeter) were done to determine the resistivity of the layers, in combination with a thickness estimation based on SEM cross sections. To check the electronic conductivity of the films, electron exchange by ferrocene reduction was studied [33]. Cyclic voltammograms of the annealed samples were measured at 10 $\mathrm{mV} \cdot \mathrm{s}^{-1}$ for 5 cycles in $0.1 \mathrm{M}$ of ferrocene (Sigma Aldrich, $\geq 98 \%$ ) in anhydrous acetonitrile (ATN, VWR, >99,9\%), using a $\mathrm{Ag} / \mathrm{AgNO}_{3}(10 \mathrm{mM})$ in $0.1 \mathrm{M} \mathrm{Bu}_{4} \mathrm{NPF}_{6}$ as reference electrode, and acetonitrile with $0.1 \mathrm{M} \mathrm{Bu}_{4} \mathrm{NPF}_{6}$ as counter electrode. Deposited films were used as working electrode. Ferrocene solution was bubbled with $\mathrm{N}_{2}$ for 2-3 mins before the start of the experiment. A reference measurement was made on a commercial ITO sample (coated boro-aluminosilicate glass, Sigma Aldrich). Cyclic voltammetry and galvanostatic measurements were done with an Autolab PGSTAT128N, using a three electrode setup in combination with a custom made Teflon cell, similar to Donders et al. [34], filled with 1.0 M $\mathrm{LiClO}_{4}$ dissolved in polycarbonate (Soulbrain MA). The sample was used as the working electrode, metallic lithium (99,9\% Sigma Aldrich) served as the counter and reference electrodes. During the galvanostatic measurements, the test cells were operated with 
E.J. van den Ham et al. - Published in Journal of Power Sources 348: 130-137 (30 April 2017)

various currents ranging from 1.5 to $237 \mu \mathrm{A}$ between 1.75 and $3.5 \mathrm{~V}$, at $20.0^{\circ} \mathrm{C}$ via a custom made temperature control chamber inside an Ar-filled glovebox.

\section{Results and discussion}

\subsection{Thermal decomposition of the In-Sn-precursor}

While decomposing the mixed In-Sn dried precursor gel, the mass loss curve (Figure 1) shows similar features known from other citrato-metal decompositions [30,35-37]. First of all, loss of residual solvent, water and ethanol, occurs up to $100^{\circ} \mathrm{C}$, followed by the onset of the first main decomposition peak $\left(120-250^{\circ} \mathrm{C}\right)$. This results in a gradual slope from $250^{\circ} \mathrm{C}$ till $475^{\circ} \mathrm{C}$, where the onset of the final decomposition reaction starts. Finally, the reaction is completed at $510^{\circ}$. The total mass loss after the final decomposition is $88 \%$, due to decomposition of the citrato complexes. Besides the $\mathrm{In}^{3+}$ citrate complex, which is a polynuclear complex with a 1:1 In:CA ratio at $\mathrm{pH} 7$ [38], and the citrato-peroxo-Sn ${ }^{4+}$ complex (1:2 Sn:CA ratio) [37], an excess of uncomplexed citric acid is present, forming ammonium citrate with the added ammonia. Van Werde et al. showed that oxidative decomposition of ammonium citrate decomposition results in strong $\mathrm{NH}_{3}$ and $\mathrm{CO}_{2}$ evolution between 150 and $280^{\circ} \mathrm{C}$, as well as decomposition of nitrogen containing compounds that decompose between 300 and $650^{\circ} \mathrm{C}$ [39]. Since decomposition of ammonium citrate mostly coincides with the indium and tin complex decomposition, specific features related to ammonium citrate decomposition are hard to discriminate in the mixed metal citrate precursor [40].

As $90 \%$ of the mixed ITO precursor is composed of the indium precursor, the decomposition profile of the mixed ITO precursor (Figure 1) shows great resemblance with the decomposition of the (separate) indium precursor (Figure S1a). Small differences can however be observed while comparing the mixed ITO and indium precursor, this is seen most clearly while comparing the derivative curves (Figure 1 and S1a). At 130 and $470^{\circ} \mathrm{C}$ shoulders can be observed, as well as a (local) maximum at $220^{\circ} \mathrm{C}$, representing decomposition reactions related to the citrato-peroxo-Sn ${ }^{4+}$ complex 
E.J. van den Ham et al. - Published in Journal of Power Sources 348: 130-137 (30 April 2017)

(Figure S1b). While approaching the final weight at $510^{\circ} \mathrm{C}$, (partial) crystallization is expected to start slightly before or immediately at this temperature. The conversion of $\mathrm{M}-\mathrm{O}-\mathrm{C}$ bonds to $\mathrm{M}-\mathrm{O}-\mathrm{M}$ bonds (where $M=S n, I n$ ) readily leads to crystallization at these temperatures, as amorphous ITO is reported to crystallize at temperatures as low as $125^{\circ} \mathrm{C}$ [41]. However, to increase the conductivity, sufficiently high temperatures were chosen (up to $800^{\circ} \mathrm{C}$ ), similar to other ITO films prepared by wetchemical processing $[32,42]$.

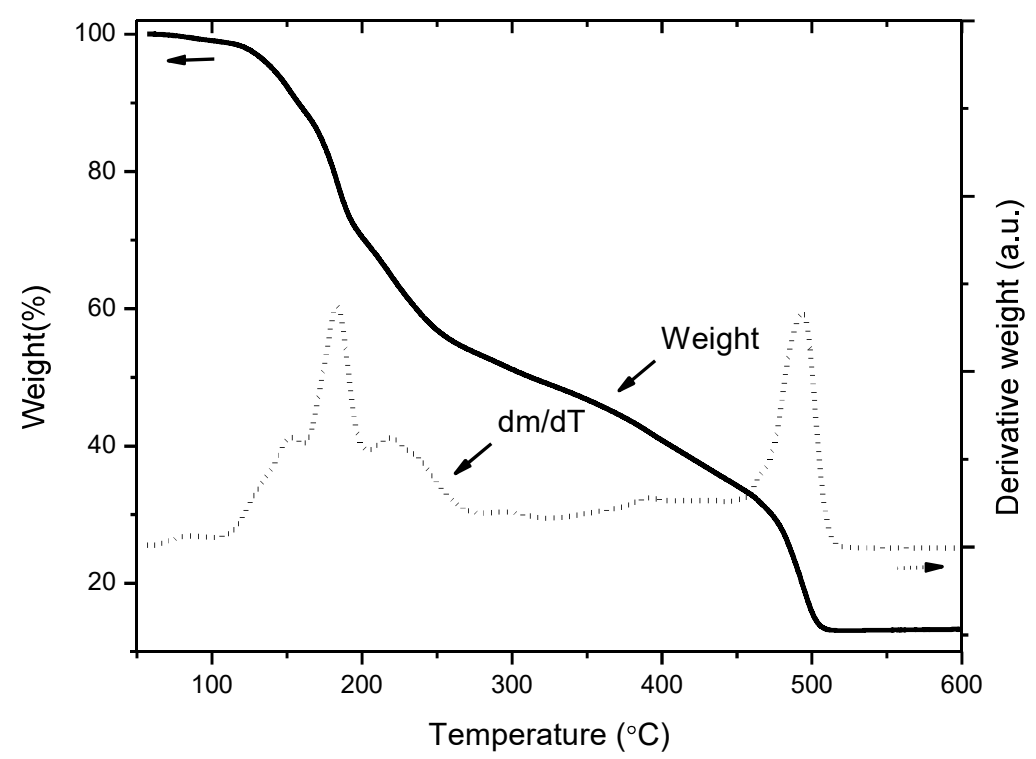

Figure 1: TGA and DTG of the ITO citrate-based precursor $(10 \% \mathrm{Sn})$, with a heating rate of $10^{\circ} \mathrm{C} \cdot \mathrm{min}^{-1}$ in dry air.

\subsection{Roughness and morphology of ITO films}

The deposition temperature, i.e. the temperature of the substrate during spray deposition, greatly influences the morphology of the films deposited on planar substrates (Figure 2). A lower deposition temperature leads to larger droplets because less evaporation occurs before the droplets hit the substrate [28]. In addition, coalescence is more likely to occur at low temperatures since the droplets have more time to flow over the surface [43]. This results in large droplets on the substrate surface, leading to rough surfaces. At higher temperatures, smaller droplets are deposited due to solvent evaporation. In addition, droplet immobilization is enhanced and coalescence is less likely to occur. It 
is thought that the combination of smaller droplets and reduced coalescence is the reason that higher deposition temperature yields smoother films.

As can be observed for all deposition temperatures measured (Figure 2), the intermediate annealing leads to a large roughness reduction. Roughness arising from the deposition is reduced since height differences (i.e. roughness) disappear due to densification during the anneal. Hence, (rough) low temperature deposited films smoothen upon annealing, but they do not surpass (smooth) high temperature deposited films that also densify during annealing. This is the reason why the so-called 'intermediate annealing' was applied during the synthesis, meaning that every 5 deposition cycles the substrate is submitted to a short high temperature anneal $\left(600^{\circ} \mathrm{C}\right)$ to decompose the precursor before depositing the next batch of deposition cycles.

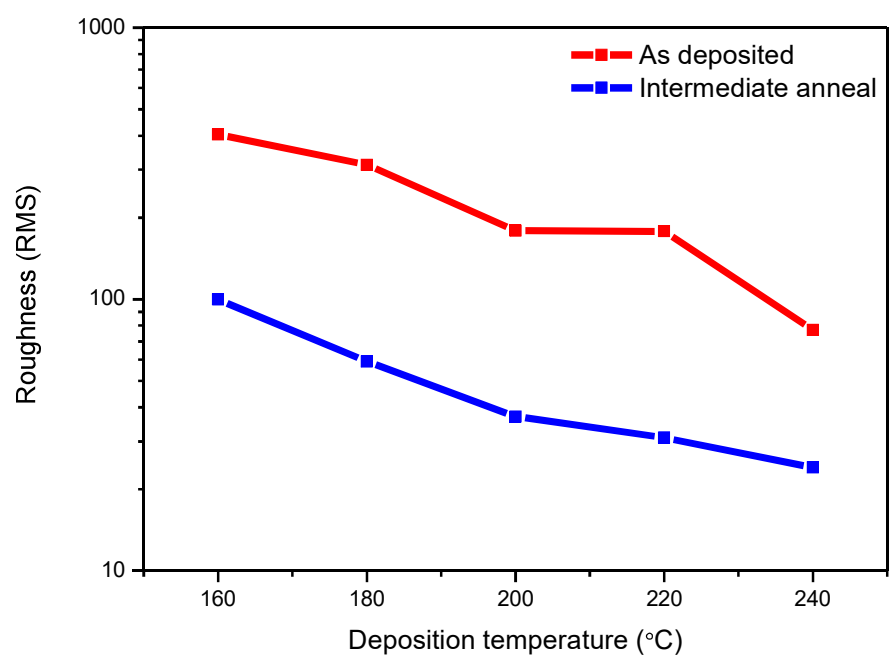

Figure 2: Profilometry results of In-Sn-precursor (10\% Sn) showing as-deposited and intermediate anneal ( 2 min. at $300^{\circ} \mathrm{C}$ and $600^{\circ} \mathrm{C}$ ) RMS roughness values as function of deposition temperature after 5 deposition cycles (10 mM) with ultrasonic spray deposition on Si native oxide substrates.

An example of the obtained morphology is shown in Figure S2 (after high temperature annealing). Deposition of the mixed precursor on silicon wafers with thermal oxide yielded a slightly rough, but continuous film after an anneal at $800\left(10\right.$ minutes, dry air) and $400^{\circ} \mathrm{C}\left(3\right.$ hours, $\left.\mathrm{N}_{2}\right)$. The deposition temperature used $\left(220^{\circ} \mathrm{C}\right)$ is not optimized for the most smooth result (Figure 2). 
E.J. van den Ham et al. - Published in Journal of Power Sources 348: 130-137 (30 April 2017)

However, this temperature was used in view of 3D deposition (c.f. below). Grain sizes of 20 to $40 \mathrm{~nm}$ can be distinguished, as determined by SEM (Figure S2b). The film growth rate was determined to be approximately $9 \mathrm{~nm}$ per deposition cycle (Figure S3), leading to a layer thickness between 220 and $230 \mathrm{~nm}$ for 25 deposition cycles.

Besides reduced roughness on the planar samples, the higher deposition temperatures are also favorable for the 3D deposition as observed in Figure 3. At low temperatures $\left(<190^{\circ} \mathrm{C}\right)$ a poor coating is found on the silicon micro-cylinders. The material is primarily deposited as a thick film on the bottom of the substrate, without coating the vertical areas. While assuming the deposited material consists of a slightly flowing gel at low deposition temperatures, the material flows downwards during the deposition process, yielding a layer that is primarily situated at the bottom of the microcylinders [22]. At higher deposition temperatures $\left(>210^{\circ} \mathrm{C}\right)$, the deposition can be tuned to yield an ITO coating that completely covers the micro-cylinders by forming a continuous layer from top to bottom. More specifically, $220^{\circ} \mathrm{C}$ was found to be the optimal deposition temperature (Figure S4). It is thought that the higher temperature immobilizes the gel, preventing too much flow down the micro-cylinders, therefore leading to more evenly spread precursor all over the micro-cylinders [22]. Besides the deposition temperature, which was shown to have a great influence on the coatings, the wettability of the precursor proved to be of importance. To achieve good wetting of the precursor on the micro-cylinders, the surface chemistry is optimized by tuning the substrate surface and surface tension of the precursor. It was shown before that the addition of ethanol to the aqueous citrate solution is of importance because this lowers the surface tension of the precursor, improving the wetting behavior [26]. In addition, the substrate surface was tuned by improving the hydrophilicity using a modified piranha cleaning procedure: a consecutive sulphuric acid-peroxide and ammoniaperoxide treatment (SPM/APM, also known as acid-piranha and base-piranha, respectively [31]). Without this additional cleaning, no complete coating of the entire micro-cylinders was achieved, especially with respect to the bottom part of the cylinders (c.f. Figure S5). Optimization of the surface 
chemistry, precursor wettability and deposition parameters together yields the desired result: high quality ITO layers on 3D structured scaffolds, down to the micron scale.

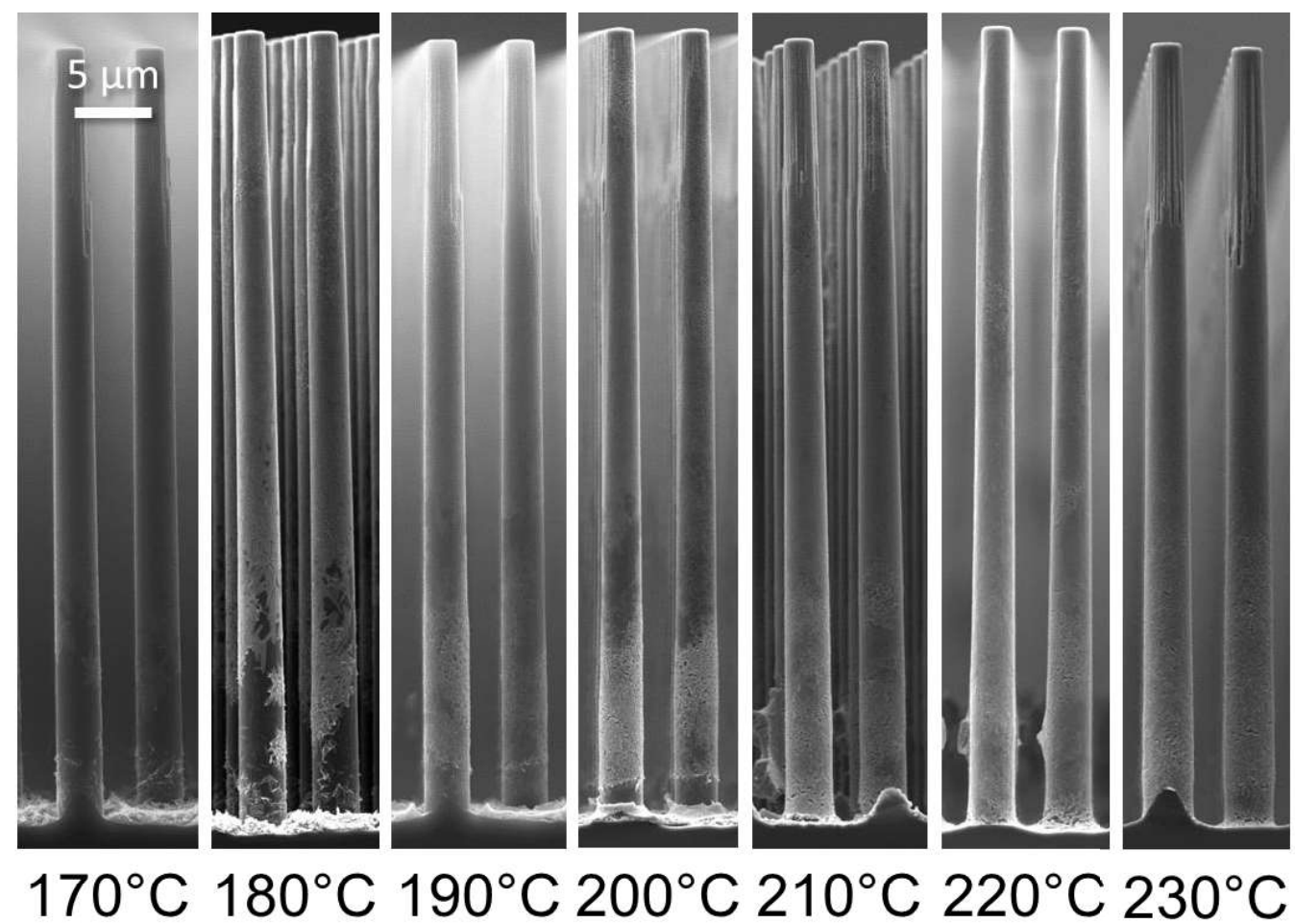

Figure 3: SEM micrograph of ITO films on Si micro-cylinders of $50 \mu \mathrm{m}$ in length, $1.5 \mu \mathrm{m}$ radius with an inter-cylinder distance of $5 \mu \mathrm{m}$; as a results of 50 spray deposition cycles with $10 \mathrm{mM}$ ITO citrate precursor, using the indicated deposition temperatures. The substrates were submitted to SPM/APM cleaning prior to deposition, and the ITO films were subjected to a post-deposition anneal at $\mathbf{6 0 0}$ for $\mathbf{1}$ hour in dry air (static). Artifacts on top of the micro-cylinders are a result of the fabrication process (not related to cleaning or ITO deposition).

Whereas the use of micro-cylinders makes it difficult to check the conformality and layer thickness, deposition on micrometer sized trench structures enables an accurate determination of the conformality (Figure 4). At a deposition temperature of $220^{\circ} \mathrm{C}$, thicknesses (determined by SEM) along the trench were found to vary from $160 \mathrm{~nm}$ at the top of the trench, down to $56 \mathrm{~nm}$ in the corner of the trench. Therefore, the conformality of the deposition (i.e. the thinnest part of the film divided by the thickest part) was determined to be $35 \%$. 


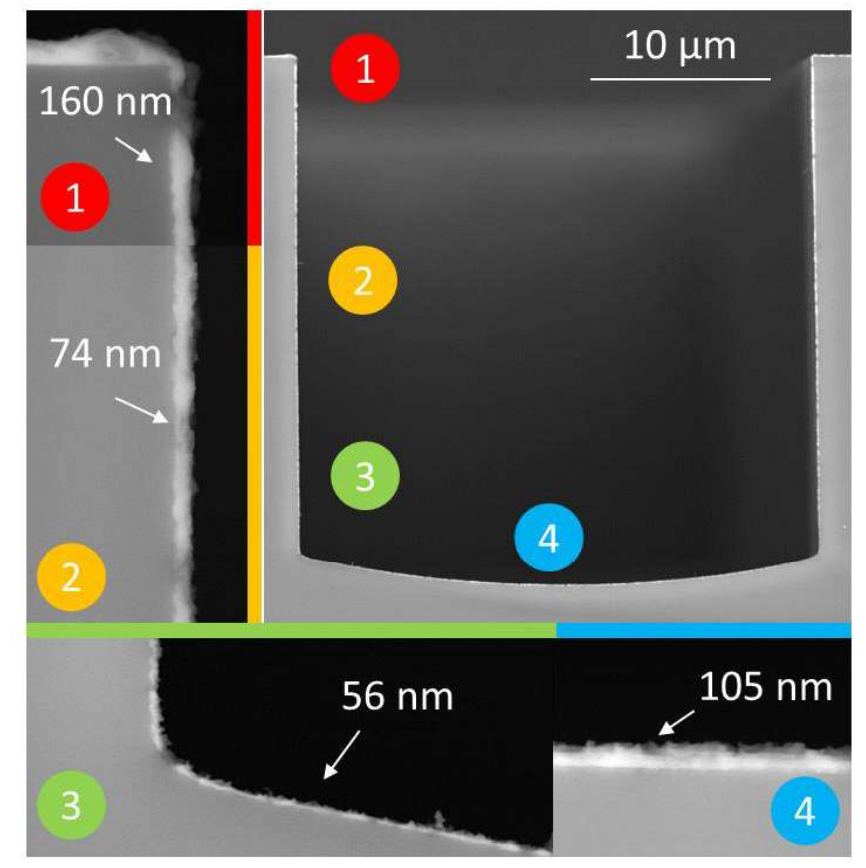

Figure 4: SEM micrograph of ITO films on Si trench structure $30 \mu \mathrm{m}$ wide and $30 \mu \mathrm{m}$ deep, as a results of $5+5$ spray deposition cycles with $10 \mathrm{mM}$ ITO citrate precursor, at a deposition temperature of $220^{\circ} \mathrm{C}$. The samples were submitted to a post-deposition anneal at $600^{\circ} \mathrm{C}$ for 1 hour in dry air (static).

Figure 5 shows the XRD results of the ITO films deposited on $\mathrm{Si}$ and $\mathrm{SiO}_{2}$. Differences in planar deposition (including $\mathrm{WO}_{3}$ deposition) will be discussed below. In general, the XRD measurements indicate that planar and 3D deposition of ITO do not differ in terms of crystallinity (Figure 5, blue and black curve, respectively). Except for the Si substrate peak, all peaks can be attributed to cubic indium oxide. Exact determination of successful Sn substitution is rather difficult on films by means of XRD, as several factors (other than Sn substitution) influence the expected increase of lattice parameters [44]. On the other hand, $\mathrm{no} \mathrm{SnO}_{2}$ or related phase(s) could be detected, suggesting that doping was indeed successful $[42,45,46]$. 


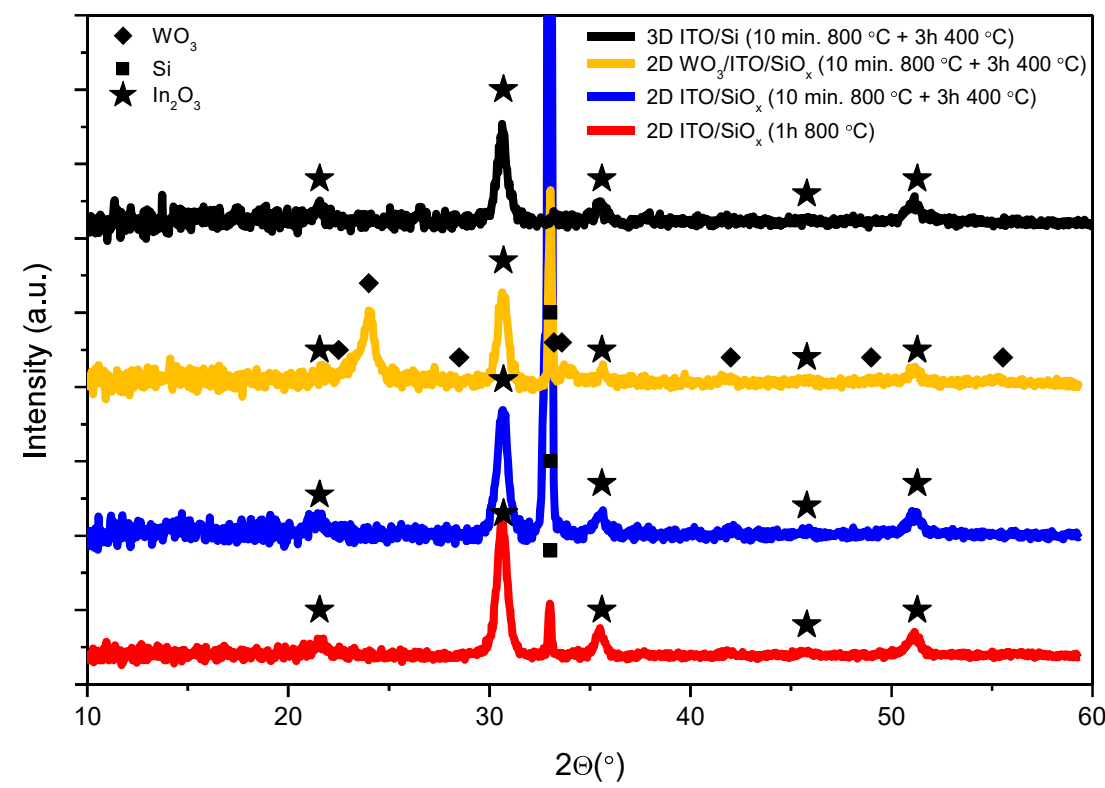

Figure 5: X-ray diffractograms of 2D and 3D ITO coated samples. 2D pristine and $\mathrm{WO}_{3}$ coated ITO films (220 nm) were deposited on a thermally grown $\mathrm{SiO}_{\mathrm{x}}$ layer $(200 \mathrm{~nm})$, as a results of 25 spray deposition cycles at $220^{\circ} \mathrm{C}$ with intermediate annealing up to $600{ }^{\circ} \mathrm{C}$ every 5 cycles. The samples were submitted to a post-deposition anneal at $800^{\circ} \mathrm{C}(10$ minutes, dry air) followed by annealing under inert conditions ( 3 hours, $400^{\circ} \mathrm{C}$ in $\left.\mathrm{N}_{2}\right)$. $\mathrm{WO}_{3}$ coated samples $(10$ cycles of $25 \mathrm{mM}$ tungsten citrate precursor) were annealed at $600^{\circ} \mathrm{C}$ in static air for 1 hour. 3D coated Si micro-cylinders, prepared similairly to Figure 3 with $220^{\circ} \mathrm{C}$ deposition temperature, were annealed at $800^{\circ} \mathrm{C}$ ( 10 minutes, dry air) followed by

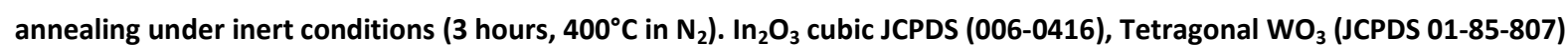
and Si (JCPDS 01-72-1088) phases are all indicated.

\subsection{Electrical properties}

For the planar samples, the resistivity values strongly depend on the applied annealing procedure, as can be observed in Table 1 . With an anneal at $600^{\circ} \mathrm{C}$ in dry air, a very high resistivity is measured (not shown). A higher annealing temperature of $800^{\circ} \mathrm{C}$ under oxidative conditions significantly reduces the resistivity, which may be due to an increased crystallinity of the samples, as substitutional $\mathrm{Sn}\left(\left[\mathrm{Sn}^{\bullet}\right]\right)$ does not contribute to conductivity in amorphous ITO [41]. Using inert annealing conditions at $800^{\circ} \mathrm{C}$, after a short oxidative anneal to decompose the residual organics, significantly improved resistivity values are obtained. A final improvement was made while following findings of Sugahara et al. [32]. While combining a short, oxidative high temperature anneal (10 
E.J. van den Ham et al. - Published in Journal of Power Sources 348: 130-137 (30 April 2017)

minutes, $800^{\circ} \mathrm{C}$, dry air) with a much longer, low temperature anneal under inert conditions ( 3 hours, $400^{\circ} \mathrm{C}, \mathrm{N}_{2}$ ), the best resistivity value measured amounted $9.9 \cdot 10^{-3} \Omega \cdot \mathrm{cm}$. No significant differences in crystallinity could be observed with XRD between samples annealed at $800^{\circ} \mathrm{C}$ for 1 hour or 10 minutes at $800^{\circ} \mathrm{C}$ combined with 3 hours at $400^{\circ} \mathrm{C}$ under inert conditions (Figure 5). Processing under inert conditions therefore suggests an increase in the oxygen vacancies $\left(V_{0} \bullet \bullet\right.$ [44]. While comparing the conductivity results with other wet-chemical synthesis routes, it must be noted that the resistivity is an order of magnitude higher than recent results obtained by spin-coating [32]. The reason that the resistivity of the films obtained by ultrasonic spray deposition in the current study is higher, is mainly sought in a higher surface roughness. For spin-coating, sub-nanometer values were reached [32], whereas the roughness values obtained in this study are approximately two orders of magnitude higher (Figure 2).

Table 1: Resistivity values measured by the 'van der Pauw' method in combination with SEM to determine the layer thickness as function of various annealing conditions. The ITO films $(220 \mathrm{~nm})$ were deposited on a thermally grown SiOx layer $(200 \mathrm{~nm})$, as a result of 25 spray deposition cycles at $220^{\circ} \mathrm{C}$ with intermediate annealing up to $600{ }^{\circ} \mathrm{C}$ every 5 cycles. The standard deviation of all samples was below $1 \cdot 10^{-4} \Omega \cdot \mathrm{cm}$.

\begin{tabular}{|l|l|}
\hline Anneal & Resistivity $(\Omega \cdot \mathrm{cm})$ \\
\hline $800^{\circ} \mathrm{C}$ 1h DA & $3.2 \cdot 10^{-2}$ \\
\hline $800^{\circ} \mathrm{C} 1 \mathrm{~h} \mathrm{Ar}$ & $2.8 \cdot 10^{-2}$ \\
\hline $800^{\circ} \mathrm{C} 5 \mathrm{~min} . \mathrm{DA}+3 \mathrm{~h} \mathrm{~N} \mathrm{~N}_{2}$ & $9.9 \cdot 10^{-3}$ \\
\hline
\end{tabular}

The electrode / current collecting-properties in 3D cannot be probed directly by the 'Van der Pauw' method, but qualitative assessment of the ITO layer functionality was done by measuring ferrocene reduction (Figure 6). Upon successful electron transfer, ferrocene is reduced to ferrocenium at the surface. Hence, ferrocene reactivity is a measure for the conductivity of the ITO coating $[33,47]$. For the planar samples - which did allow direct determination of the resistivity by 'Van der Pauw' method - a clear difference is observed while comparing the (non-conductive) uncoated sample $\left(\mathrm{SiO}_{x} / \mathrm{Si}\right)$ and ITO coated sample in the cyclic voltammogram (Figure 6). The 
uncoated sample hardly shows any response due to the non-conductive $\mathrm{SiO}_{x}$ at the interface, whereas the ITO coated sample shows a reduction of ferrocene at the ITO surface at $-0.04 \mathrm{~V}$. However, no clear oxidation peak is observed. While comparing these results with a commercial ITO film reference measurement (Figure S6), the lack of an oxidation peak is explained. The commercial ITO with a lower resistivity hardly shows an oxidation peak either, although a broad low intensity oxidation can be noted at $0.23 \mathrm{~V}\left(\mathrm{vs} . \mathrm{Ag} / \mathrm{AgNO}_{3}\right)$. Hence, the higher resistivity of the spray-deposited ITO coating leads to a less intense oxidation peak, making it unmeasurable (Figure 6).

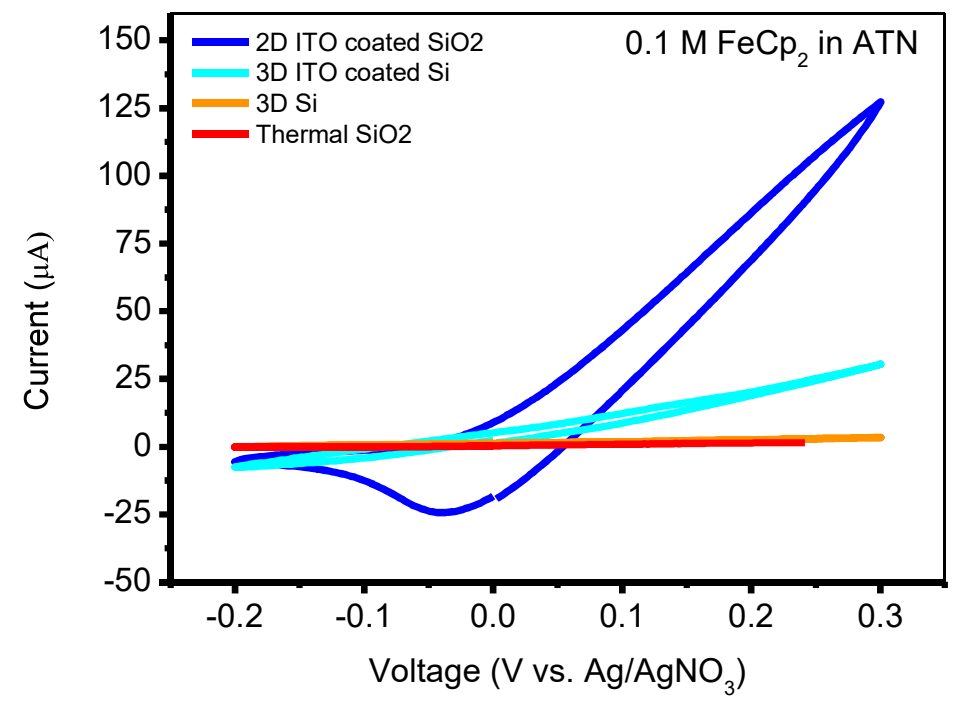

Figure 6: Cyclic voltammogram showing electron transfer of ferrocene on planar samples $\left(1 \mathrm{mV} \cdot \mathrm{s}^{-1}\right)$. The ITO films measured were deposited in accordance with samples shown in Figure S2 and S4. Both ITO coated samples were annealed 10 minutes at $800^{\circ} \mathrm{C}$ (dry air) and 3 hours at $400^{\circ} \mathrm{C}$ (nitrogen).

The same experiment was done on ITO coated micro-cylinders, but no clear oxidation and reduction could be observed here as well. The ITO coatings on 3D Si micro-cylinders are significantly thinner (Figure 3 and 4) with a higher resistance compared to planar films, resulting in a lack of reduction and oxidation peaks for the 3D measurements in the cyclic voltammogram (Figure 6). However, these measurements do suggest a slight increase in conductivity with respect to electron transfer reactions at the surface for the 3D ITO coating compared to non-coated 3D Si micro-cylinders. 
E.J. van den Ham et al. - Published in Journal of Power Sources 348: 130-137 (30 April 2017)

\subsection{Towards Li-ion battery applications}

In general, any candidate current collector within the field of (3D) Li-ion batteries requires low electrochemical reactivity with respect to $\mathrm{Li}^{+}$. For example, TiN shows hardly any electrochemical activity, even at low voltages vs. $\mathrm{Li}^{+} / \mathrm{Li}$ [17]. To judge if the ITO coatings are of interest within the field of Li-ion batteries, the electrochemical activity of these coatings was investigated. By means of cyclic voltammetry with metallic lithium as reference and counter electrodes in a non-aqueous electrolyte, the insertion and extraction of $\mathrm{Li}^{+}$into the deposited ITO was studied between 0 and $4 \mathrm{~V}$ vs. Li/ $\mathrm{Li}^{+}$ (Figure 7). Clearly, the reactivity of the deposited layer strongly depends on the voltage range applied. Above $1.6 \mathrm{~V}$, no redox reactions take place, implying that the material is stable within this voltage range. At lower potentials, two reductions and one large oxidation can be observed (indicated with 1, 2 and 3 in Figure 7). The reductions ( 0.7 and $0 \mathrm{~V}$ ) might be related to $\mathrm{Sn}^{4+}$ reduction and alloying of lithium with reduced Sn, respectively $[48,49]$. Although no clear indications of overlapping peaks are present, the $0.7 \mathrm{~V}$ reduction peak (indicated by 1 in Figure 7) can also be associated with indium reduction below $1.0 \mathrm{~V}[50,51]$, as well as SEl formation $[48,49]$. The latter seems more plausible since irreversible reactions are clearly occurring. Finally, the reduction peak at $0 \mathrm{~V}$ and oxidation at $1.3 \mathrm{~V}$ (indicated by 2 and 3, Figure 7) can also be due to $\mathrm{SiO}_{2}$ (de)intercalation of lithium [52], although the negligible electronic conductivity of this material makes these reactions unlikely. 


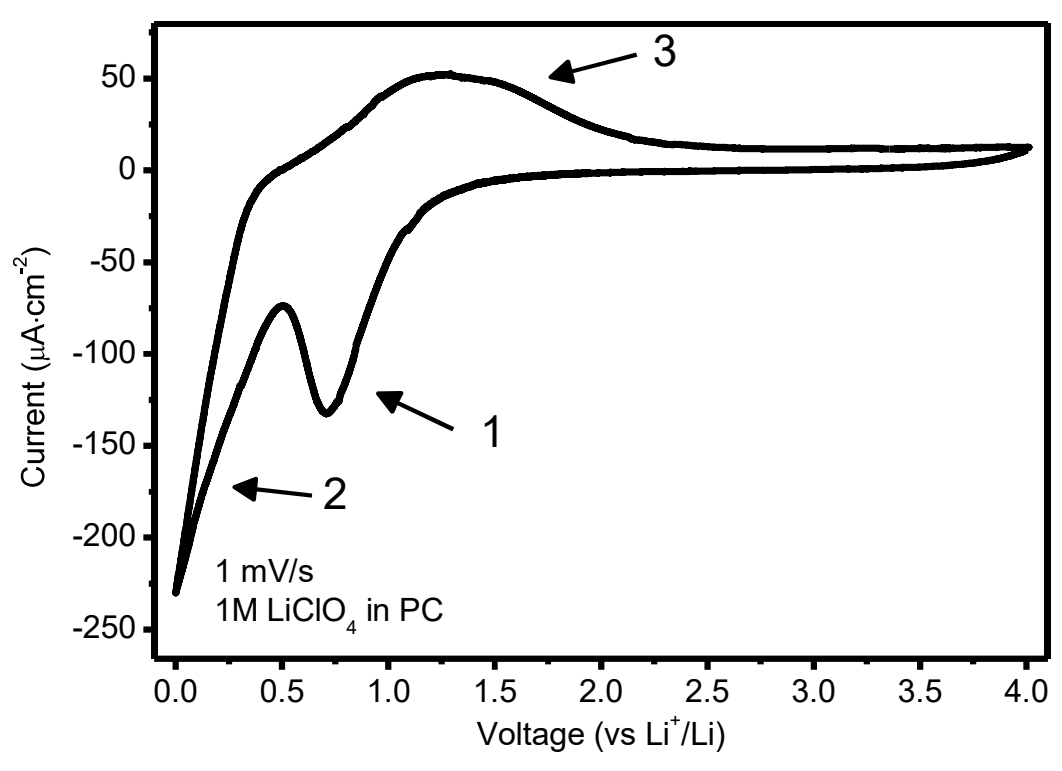

Figure 7: Cyclic voltammogram showing reactivity of ITO films with lithium (ions). The ITO films (220 nm) were deposited on thermally grown SiOx layer $(200 \mathrm{~nm})$, as a results of 25 spray depositions with intermediate annealing up to $600^{\circ} \mathrm{C}$ every 5 cycles.

In view of applications as a current collector for Li-ion batteries, lithium reactivity with the ITO and / or substrate is undesired upon battery operation, meaning that not all battery electrode materials are suitable for direct deposition on top of the ITO. The stability at high potentials makes the ITO suitable to be combined with positive electrode materials (also referred to as 'cathodes') such as $\mathrm{LiCoO}_{2}$ [34]. On the negative electrode side, electrodes with (de)intercalation voltages below $1.5 \mathrm{~V}$ such as metallic lithium and lithiated graphite should be avoided, as these materials would instantly react with the ITO and lead to loss of charge. This means that combination with high voltage negative electrodes ('anodes') such as $\mathrm{Li}_{4} \mathrm{Ti}_{5} \mathrm{O}_{12}[53,54], \mathrm{TiO}_{2}[48,55]$ and $\mathrm{WO}_{3}[29,56]$ should be possible.

In this study, a proof-of-principle is shown using the latter material: $\mathrm{WO}_{3}$. To study the influence on present crystalline phases, pristine ITO and $\mathrm{WO}_{3}$-coated substrates were measured by XRD (Figure 5). Upon coating with $\mathrm{WO}_{3}$, the peaks assigned to ITO remain present, indicating that at least part of the crystalline ITO coating is preserved. Furthermore, no secondary phases were observed; XRD measurements yield no indications of ITO degradation or side reactions occurring during the 
E.J. van den Ham et al. - Published in Journal of Power Sources 348: 130-137 (30 April 2017)

annealing required to crystallize $\mathrm{WO}_{3}\left(1\right.$ hour at $\left.600^{\circ} \mathrm{C}\right)$. It is however possible that the increase in oxygen vacancies in the ITO, induced by the long, relative low temperature anneal ( 3 hours at $400^{\circ} \mathrm{C}$ in $\mathrm{N}_{2}$ ), is partly reversed. $\mathrm{WO}_{3}$ peaks are clearly observed for the $\mathrm{WO}_{3}$-coated ITO in Figure 5 ; the sample consists of tetragonal $\mathrm{WO}_{3}$. The same result was recently found for $\mathrm{WO}_{3}$ films on $\mathrm{Pt}$ and $\mathrm{TiN}$ coated substrates [29].

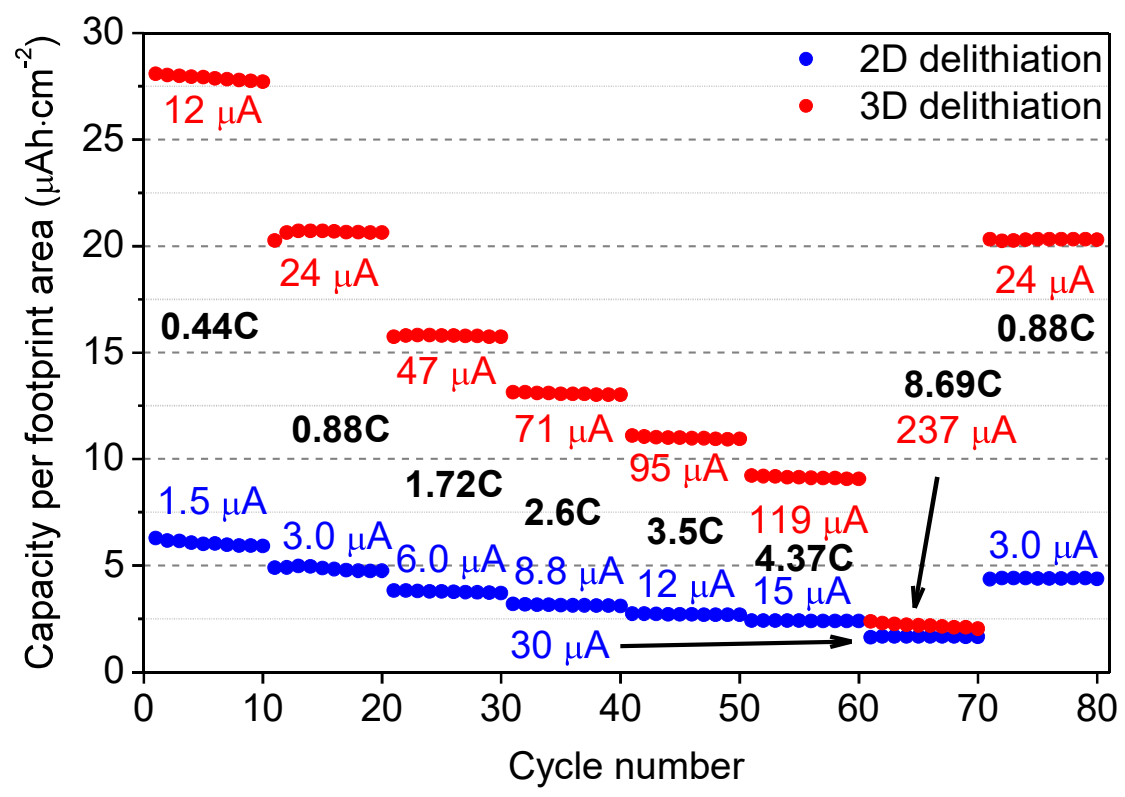

Figure 8: Delithiation results of planar (2D) and 3D $\mathrm{WO}_{3}$ coated ITO on Si micro-cylinders with aspect ratio 10. The planar and 3D samples were coated by 2 / 25 and 16 / 50 deposition cycles of W-precursor / In-Sn-precursor, annealed at $800^{\circ} \mathrm{C}(10$ minutes $)+400^{\circ} \mathrm{C}$ ( 3 hours) in dry air $+N_{2}$. Cut-off voltages of 1.75 and $3.5 \mathrm{~V}\left(\mathrm{vs}\right.$. Li/ $\left./ \mathrm{Li}^{+}\right)$were chosen, with discharge currents per $\mathrm{cm}^{2}$.

Although the 3D ITO coating suffers from conductivity limitations for the ferrocene reduction (Figure 6), Figure 8 and S7 are direct evidence for functionality of the 3D ITO coatings. The planar and 3D samples, the latter yielding an 8-fold surface enhancement, were compared via galvanostatic cycling (Figure 8). The same current per amount of deposited material is applied (i.e. 3D samples consist of 16 deposition cycles, measured with an 8-fold current of the planar samples consisting of 2 deposition cycles). With an 8-fold increase of the active material and electrode surface for current collection (due to the use of ITO coated Si micro-cylinders), an 8-fold capacity increase would be 
E.J. van den Ham et al. - Published in Journal of Power Sources 348: 130-137 (30 April 2017)

expected while applying the same current density (per coating area). In practice this turned out to be an over 4-fold capacity increase for 3D compared to planar samples (Figure 6 and S7). Although this is not as high as theoretically possible, it does surpass previous results established within our labs with TiN as a current collector, which led to a less than 3-fold capacity improvement [22]. To make sure that this difference in capacity is not related to the ITO layer itself, galvanostatic measurements on pristine ITO were done, yielding a capacity of $53 \mathrm{nAh} \cdot \mathrm{cm}^{-2}$ (with $1.5 \mu \mathrm{A} \cdot \mathrm{cm}^{2}$ ) within this voltage region. This implies that ITO has a negligible storage capacity during these measurements, and that the capacity measured indeed belongs to the active $\left(\mathrm{WO}_{3}\right)$ material. The main reason why the 8 -fold capacity improvement is not entirely reached is sought in the imperfect deposition of $\mathrm{WO}_{3}$ leading to an uneven current distribution [22]. This is also expressed in the larger voltage drop in 3D compared to planar while viewing the charge/discharge curves obtained by galvanostatic cycling (Figure S6). This is in agreement with Figure 6, indicating that the total resistance of the 3D ITO coatings is higher than planar ITO, as was discussed earlier. Both the imperfect deposition of $\mathrm{WO}_{3}$, as well as the higher resistance of the 3D ITO (compared to planar ITO), cause a slow drop of the capacity enhancement down to a 3.2-fold improvement at $119 \mu \mathrm{A}$ per $\mathrm{cm}^{2}$ footprint (15 $\mu \mathrm{A}$ per $\mathrm{cm}^{2}$ coating). This illustrates that the combined 3D stack is not perfect, but 3D enhanced capacity is achieved up to relatively large currents. However, while further increasing to even larger currents of $237 \mu \mathrm{A}$ per $\mathrm{cm}^{2}$ footprint / 30 $\mu \mathrm{A}$ per $\mathrm{cm}^{2}$ coating, the capacity of both planar and 3D samples drops significantly, implying that a kinetic drop-off is reached in terms of $\mathrm{Li}^{+}$diffusion and / or electronic conductivity of the active material $\left(\mathrm{WO}_{3}\right)$.

\section{Conclusions}

The chemical solution deposition route, using citrate based precursors in combination with ultrasonic spray deposition, proved to be a very versatile route for the deposition of a 3D structured electrode / current collector material. Surface chemistry, precursor chemistry and deposition temperature proved to be of vital importance for successful 3D deposition with ultrasonic spray 
E.J. van den Ham et al. - Published in Journal of Power Sources 348: 130-137 (30 April 2017)

deposition. The study case aimed at implementation in 3D all-solid-state Li-ion batteries, led to an over 4-fold capacity increase due to the use of 3D architectures. This illustrates the potential of this approach. Although the use of the ITO electrode already yields remarkable results for the field of 3D Li-ion batteries within the constraints dictated by the electrochemical stability of ITO, the main future challenge lies in roughness reduction to decrease the resistivity, thereby limiting the required film thickness and yielding more space for active (energy) materials. The outcome of this study is of interest to other applications as well, such as 3D LED or photovoltaic applications. However, for these applications new strategies to reach comparable results with lower annealing temperatures should be investigated, as the annealing temperature $\left(800^{\circ} \mathrm{C}\right)$ remain a bottleneck for device integration with ITO as a top electrode. Nevertheless, this study underlines the potential the wet-chemical approach has in tackling the (smart materials) challenges of tomorrow.

\section{References}

[1] A.G. Tamirat, W.-N. Su, A.A. Dubale, C.-J. Pan, H.-M. Chen, D.W. Ayele, J.-F. Lee, B.-J. Hwang, Efficient photoelectrochemical water splitting using three dimensional urchin-like hematite nanostructure modified with reduced graphene oxide, J. Power Sources. 287 (2015) 119-128. doi:10.1016/j.jpowsour.2015.04.042.

[2] Z. Pan, Y. Qiu, J. Yang, F. Ye, Y. Xu, X. Zhang, M. Liu, Y. Zhang, Ultra-endurance flexible all-solidstate asymmetric supercapacitors based on three-dimensionally coated $\mathrm{MnOx}$ nanosheets on nanoporous current collectors, Nano Energy. 26 (2016) 610-619. doi:10.1016/j.nanoen.2016.05.053.

[3] R. Pietruszka, B.S. Witkowski, S. Gieraltowska, P. Caban, L. Wachnicki, E. Zielony, K. Gwozdz, P. Bieganski, E. Placzek-Popko, M. Godlewski, New efficient solar cell structures based on zinc oxide nanorods, Sol. Energy Mater. Sol. Cells. 143 (2015) 99-104. doi:10.1016/j.solmat.2015.06.042.

[4] A. Waag, X. Wang, S. Fündling, J. Ledig, M. Erenburg, R. Neumann, M. Al Suleiman, S. Merzsch, J. Wei, S. Li, H.H. Wehmann, W. Bergbauer, M. Straßburg, A. Trampert, U. Jahn, H. Riechert, The nanorod approach: GaN NanoLEDs for solid state lighting, Phys. Status Solidi. 8 (2011) 2296-2301. doi:10.1002/pssc.201000989.

[5] B.O. Jung, S.-Y. Bae, S. Lee, S.Y. Kim, J.Y. Lee, Y. Honda, H. Amano, Emission Characteristics of InGaN/GaN Core-Shell Nanorods Embedded in a 3D Light-Emitting Diode., Nanoscale Res. Lett. 11 (2016) 215. doi:10.1186/s11671-016-1441-6. 
[6] J.W. Long, B. Dunn, D.R. Rolison, H.S. White, Three-Dimensional Battery Architectures, Chem. Rev. 104 (2004) 4463-4492. doi:10.1021/cr020740l.

[7] J.F.M. Oudenhoven, L. Baggetto, P.H.L. Notten, All-Solid-State Lithium-lon Microbatteries: A Review of Various Three-Dimensional Concepts, Adv. Energy Mater. 1 (2011) 10-33.

[8] P.H.L. Notten, F. Roozeboom, R.A.H. Niessen, L. Baggetto, 3-D Integrated All-Solid-State Rechargeable Batteries, Adv. Mater. 19 (2007) 4564-4567.

[9] P. Knauth, Inorganic solid Li ion conductors: An overview, Solid State lonics. 180 (2009) 911916. doi:10.1016/j.ssi.2009.03.022.

[10] G. Oltean, M. Valvo, L. Nyholm, K. Edström, On the electrophoretic and sol-gel deposition of active materials on aluminium rod current collectors for three-dimensional Li-ion microbatteries, Thin Solid Films. 562 (2014) 63-69. doi:10.1016/j.tsf.2014.03.069.

[11] C.P. Yang, Y.X. Yin, S.F. Zhang, N.W. Li, Y.G. Guo, Accommodating lithium into 3D current collectors with a submicron skeleton towards long-life lithium metal anodes., Nat. Commun. 6 (2015) 8058. doi:10.1038/ncomms9058.

[12] K.S. Park, J.G. Kang, Y.J. Choi, S. Lee, D.-W. Kim, J.-G. Park, Long-term, high-rate lithium storage capabilities of $\mathrm{TiO} 2$ nanostructured electrodes using 3D self-supported indium tin oxide conducting nanowire arrays, Energy Environ. Sci. 4 (2011) 1796. doi:10.1039/c0ee00804d.

[13] S. Ni, X. Lv, T. Li, X. Yang, L. Zhang, Preparation of Cu2O-Cu anode for high performance Li-ion battery via an electrochemical corrosion method, Electrochim. Acta. 109 (2013) 419-425. doi:10.1016/j.electacta.2013.07.088.

[14] S. Ni, X. Lv, J. Ma, X. Yang, L. Zhang, A novel electrochemical reconstruction in nickel oxide nanowalls on $\mathrm{Ni}$ foam and the fine electrochemical performance as anode for lithium ion batteries, J. Power Sources. 270 (2014) 564-568. doi:10.1016/j.jpowsour.2014.07.137.

[15] J.H. Um, H. Park, Y.-H. Cho, M.P.B. Glazer, D.C. Dunand, H. Choe, Y.-E. Sung, 3D interconnected SnO 2 -coated Cu foam as a high-performance anode for lithium-ion battery applications, RSC Adv. 4 (2014) 58059-58063. doi:10.1039/C4RA12297F.

[16] M. Yao, K. Okuno, T. Iwaki, T. Awazu, T. Sakai, Long cycle-life LiFePO4/Cu-Sn lithium ion battery using foam-type three-dimensional current collector, J. Power Sources. 195 (2010) 2077-2081. doi:10.1016/j.jpowsour.2009.10.014.

[17] L. Baggetto, H.C.M. Knoops, R. a. H. Niessen, W.M.M. Kessels, P.H.L. Notten, 3D negative electrode stacks for integrated all-solid-state lithium-ion microbatteries, J. Mater. Chem. 20 (2010) 3703. doi:10.1039/b926044g.

[18] H.C.M. Knoops, L. Baggetto, E. Langereis, M.C.M. van de Sanden, J.H. Klootwijk, F. Roozeboom, R. a. H. Niessen, P.H.L. Notten, W.M.M. Kessels, Deposition of TiN and TaN by Remote Plasma ALD for Cu and Li Diffusion Barrier Applications, J. Electrochem. Soc. 155 (2008) G287. doi:10.1149/1.2988651. 
[19] J. Dendooven, R.K. Ramachandran, K. Devloo-Casier, G. Rampelberg, M. Filez, H. Poelman, G.B. Marin, E. Fonda, C. Detavernier, Low-Temperature Atomic Layer Deposition of Platinum Using (Methylcyclopentadienyl)trimethylplatinum and Ozone, J. Phys. Chem. C. 117 (2013) 20557-20561. doi:10.1021/jp403455a.

[20] T. Dobbelaere, F. Mattelaer, J. Dendooven, P. Vereecken, C. Detavernier, Plasma-Enhanced Atomic Layer Deposition of Iron Phosphate as a Positive Electrode for 3D Lithium-Ion Microbatteries, Chem. Mater. 28 (2016) 3435-3445. doi:10.1021/acs.chemmater.6b00853.

[21] N.C. Saha, H.G. Tompkins, Titanium nitride oxidation chemistry: An x-ray photoelectron spectroscopy study, J. Appl. Phys. 72 (1992) 3072. doi:10.1063/1.351465.

[22] E.J. van den Ham, S. Gielis, M.K. Van Bael, A. Hardy, Ultrasonic Spray Deposition of Metal Oxide Films on High Aspect Ratio Microstructures for 3D All-solid-state Li-ion Batteries, ACS Energy Lett. 1 (2016) 1184-1188. doi:10.1021/acsenergylett.6b00449.

[23] B.H. Kong, M.K. Choi, H.K. Cho, J.H. Kim, S. Baek, J.-H. Lee, Conformal Coating of Conductive ZnO:Al Films as Transparent Electrodes on High Aspect Ratio Si Microrods, Electrochem. SolidState Lett. 13 (2010) K12. doi:10.1149/1.3267051.

[24] J.W. Elam, D. a. Baker, A.B.F. Martinson, M.J. Pellin, J.T. Hupp, Atomic Layer Deposition of Indium Tin Oxide Thin Films Using Nonhalogenated Precursors, J. Phys. Chem. C. 112 (2008) 1938-1945. doi:10.1021/jp7097312.

[25] M. Kevin, G.H. Lee, G.W. Ho, Non-planar geometries of solution processable transparent conducting oxide: from film characterization to architectured electrodes, Energy Environ. Sci. 5 (2012) 7196. doi:10.1039/c2ee21296j.

[26] S. Gielis, A. Hardy, M.K. Van Bael, Conformal coating on three-dimenstional substrates, EP 2 947178 A1, 2015.

[27] H.L. Berger, D.F. Mowbray, R.A. Copemand, R.J. Russel, Ultrasonic atomizing nozzle and method, US 7,712,680 B2, 2010.

[28] D. Perednis, L.J. Gauckler, Thin Film Deposition Using Spray Pyrolysis, J. Electroceramics. 14 (2005) 103-111. doi:10.1007/s10832-005-0870-x.

[29] E.J. van den Ham, K. Elen, I. Kokal, M.B. Yagci, N. Peys, G. Bonneux, F. Ulu, W. Marchal, M. Van Bael, A. Hardy, From liquid to thin film: colloidal suspensions for tungsten oxide as an electrode material for Li-ion batteries, RSC Adv. 6 (2016) 51747-51756. doi:10.1039/C6RA08769H.

[30] A. Stanulis, A. Hardy, C. De Dobbelaere, J. D'Haen, M. Van Bael, A. Kareiva, SnO2 thin films from an aqueous citrato peroxo Sn(IV) precursor, J. Sol-Gel Sci. Technol. 62 (2012) 57-64. doi:10.1007/s10971-012-2683-0.

[31] M.K. Van Bael, D. Nelis, A. Hardy, D. Mondelaers, K. Van Werde, J. D'Haen, G. Vanhoyland, H. Van den Rul, J. Mullens, L.C. Van Poucke, F. Frederix, D.J. Wouters, Aqueous Chemical Solution Deposition of Ferroelectric Thin Films, Integr. Ferroelectr. 45 (2002) 113-122. 
[32] T. Sugahara, Y. Hirose, S. Cong, H. Koga, J. Jiu, M. Nogi, S. Nagao, K. Suganuma, Sol-GelDerived High-Performance Stacked Transparent Conductive Oxide Thin Films, J. Am. Ceram. Soc. 97 (2014) 3238-3243. doi:10.1111/jace.13116.

[33] Y.C. Perng, J. Cho, S.Y. Sun, D. Membreno, N. Cirigliano, B. Dunn, J.P. Chang, Synthesis of ion conducting LixAlySizO thin films by atomic layer deposition, J. Mater. Chem. A. 2 (2014) 9566. doi:10.1039/c3ta14928e.

[34] M.E. Donders, W.M. Arnoldbik, H.C.M. Knoops, W.M.M. Kessels, P.H.L. Notten, Atomic Layer Deposition of LiCoO2 Thin-Film Electrodes for All-Solid-State Li-Ion Micro-Batteries, J. Electrochem. Soc. 160 (2013) A3066-A3071. doi:10.1149/2.011305jes.

[35] N. Peys, Y. Ling, D. Dewulf, S. Gielis, C. De Dobbelaere, D. Cuypers, P. Adriaensens, S. Van Doorslaer, S. De Gendt, A. Hardy, M.K. Van Bael, V6O13 films by control of the oxidation state from aqueous precursor to crystalline phase., Dalton Trans. 42 (2013) 959-68. doi:10.1039/c2dt31857a.

[36] A. Hardy, D. Mondelaers, M.K. Van Bael, J. Mullens, L.C. Van Poucke, G. Vanhoyland, J. D'Haen, Synthesis of (Bi,La)4Ti3O12 by a new aqueous solution-gel route, J. Eur. Ceram. Soc. 24 (2004) 905-909. doi:10.1016/S0955-2219(03)00420-5.

[37] I. Truijen, M.K. Van Bael, H. Van Den Rul, J. D'Haen, J. Mullens, Synthesis of thin dense titania films via an aqueous solution-gel method, J. Sol-Gel Sci. Technol. 41 (2006) 43-48. doi:10.1007/s10971-006-0123-8.

[38] V.Y. Ivanova, V. V. Chevela, S.G. Bezryadin, Complex formation of indium(iii) with citric acid in aqueous solution, Russ. Chem. Bull. 64 (2016) 1842-1849. doi:10.1007/s11172-015-1082-4.

[39] K. Van Werde, D. Mondelaers, G. Vanhoyland, D. Nelis, M.K.V.A.N. Bael, Thermal decomposition of the ammonium zinc acetate citrate precursor for aqueous chemical solution deposition of ZnO, J. Mater. Sci. 37 (2002) 81-88.

[40] M. Rajendran, M. Subba Rao, Formation of BaTiO3 from citrate precursor, J. Solid State Chem. 113 (1994) 239-247.

[41] D.C. Paine, T. Whitson, D. Janiac, R. Beresford, C.O. Yang, B. Lewis, A study of low temperature crystallization of amorphous thin film indium-tin-oxide, J. Appl. Phys. 85 (1999) 8445. doi:10.1063/1.370695.

[42] C. Legnani, S. a. M. Lima, H.H.S. Oliveira, W.G. Quirino, R. Machado, R.M.B. Santos, M.R. Davolos, C. a. Achete, M. Cremona, Indium tin oxide films prepared via wet chemical route, Thin Solid Films. 516 (2007) 193-197. doi:10.1016/j.tsf.2007.06.137.

[43] M. Majumder, C. Rendall, M. Li, N. Behabtu, J.A. Eukel, R.H. Hauge, H.K. Schmidt, M. Pasquali, Insights into the physics of spray coating of SWNT films, Chem. Eng. Sci. 65 (2010) 2000-2008. doi:10.1016/j.ces.2009.11.042.

[44] H. Kim, C.M. Gilmore, a. Piqué, J.S. Horwitz, H. Mattoussi, H. Murata, Z.H. Kafafi, D.B. Chrisey, Electrical, optical, and structural properties of indium-tin-oxide thin films for organic lightemitting devices, J. Appl. Phys. 86 (1999) 6451. doi:10.1063/1.371708. 
[45] E. Benamar, M. Rami, C. Messaoudi, D. Sayah, a. Ennaoui, Structural, optical and electrical properties of indium tin oxide thin films prepared by spray pyrolysis, Sol. Energy Mater. Sol. Cells. 56 (1999) 125-139. doi:10.1016/S0927-0248(98)00151-2.

[46] M. Alam, D. Cameron, Investigation of annealing effects on sol-gel deposited indium tin oxide thin films in different atmospheres, Thin Solid Films. 420-421 (2002) 76-82. doi:10.1016/S0040-6090(02)00737-X.

[47] G. Zotti, G. Schiavon, S. Zecchin, A. Berlin, G. Pagani, Adsorption of Ferrocene Compounds on Indium - Tin - Oxide Electrodes. Enhancement of Adsorption by Decomposition of Ferrocenium Molecules by Oxygen, Langmuir. 14 (1998) 1728-1733.

[48] D. Deng, M.G. Kim, J.Y. Lee, J. Cho, Green energy storage materials: Nanostructured TiO2 and Sn-based anodes for lithium-ion batteries, Energy Environ. Sci. 2 (2009) 818. doi:10.1039/b823474d.

[49] D. Deng, J.Y. Lee, Hollow Core - Shell Mesospheres of Crystalline SnO 2 Nanoparticle Aggregates for High Capacity Li + Ion Storage, Chem. Mater. 20 (2008) 1841-1846.

[50] Y.L. Lo, S.C. Chou, B.J. Hwang, J.A. Elec-, The Electrochromic Behavior of Indium Tin Oxide in Propylene Carbonate Solutions, J. Electrochem. Soc. 145 (1998) 2225-2230.

[51] J. Morales, L. Sanchez, Electrochemical behaviour of SnO 2 doped with boron and indium in anodes for lithium secondary batteries, Solid State lonics. 126 (1999) 219-226.

[52] N. Yan, F. Wang, H. Zhong, Y. Li, Y. Wang, L. Hu, Q. Chen, Hollow porous SiO2 nanocubes towards high-performance anodes for lithium-ion batteries., Sci. Rep. 3 (2013) 1568. doi:10.1038/srep01568.

[53] M. Roeder, A.B. Beleke, U. Guntow, J. Buensow, A. Guerfi, U. Posset, H. Lorrmann, K. Zaghib, G. Sextl, Li4Ti5O12 and LiMn2O4 thin-film electrodes on transparent conducting oxides for allsolid-state and electrochromic applications, J. Power Sources. 301 (2016) 35-40. doi:10.1016/j.jpowsour.2015.09.063.

[54] S.Y. Tsai, K.Z. Fung, C.T. Ni, Conductivity Enhancement and Thin-Film Processing of Li4Ti5O12 (LTO) Spinel for Li Battery Applications, ECS Trans. 68 (2015) 37-43.

[55] M.J. Wang, C.F. Li, W.J. Lai, S.K. Yen, Characterization of TiO2 thin films prepared by electrolytic deposition for lithium ion battery anodes, Thin Solid Films. 520 (2012) 6744-6751. doi:10.1016/j.tsf.2012.07.029.

[56] Q. Zhong, J.R. Dahn, K. Colbow, Lithium intercalation into WO3 and the phase diagram of LixWO3, Phys. Rev. B. 46 (1992) 2554-2560.

Acknowledgements

Huguette Penxten is acknowledged for her assistance during the ferrocene reduction experiments.

Imec (Leuven, Belgium) and Prof. Phillipe Vereecken are acknowledged for providing micro-cylinder substrates. This study was partly supported by the IWT SBO SOS Lion project. 


\section{Supplementary information}

a) Indium citrate

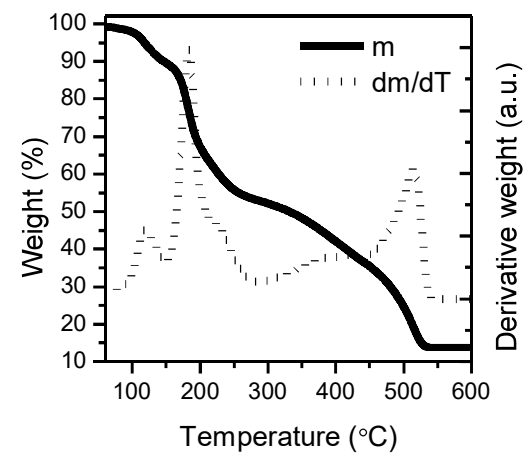

b) Tin citrate

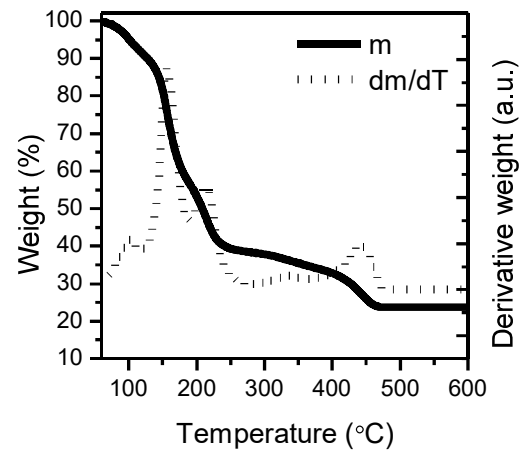

Figure S1: TGA's of (a) indium citrate precursor and (b) tin citrate, both measured with a heating rate of $10^{\circ} \mathrm{C} \cdot \mathrm{min}^{-1}$ in $\mathrm{dry}^{\mathrm{s}}$ air.
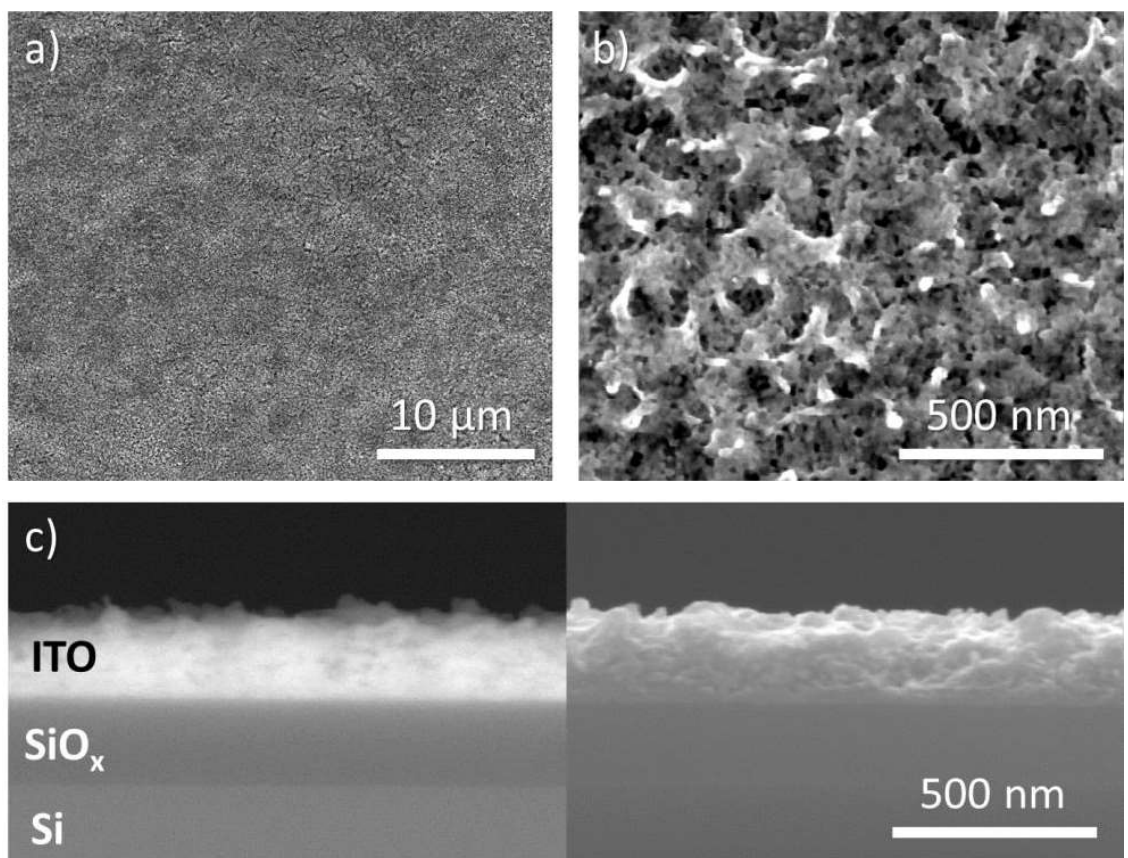

Figure S2: SEM of In-Sn-precursor $(10 \mathrm{mM}, 10 \% \mathrm{Sn})$ deposited with ultrasonic spray deposition $\left(220^{\circ} \mathrm{C}\right)$ on Si native oxide substrates. a) and b) show top view SE micrographs, c) indicates cross sections with BSE (left) and SE (right). All samples were annealed $800^{\circ} \mathrm{C}(10$ minutes $)+400^{\circ} \mathrm{C}(3$ hours $)$ in dry air $+\mathrm{N} 2$. 
E.J. van den Ham et al. - Published in Journal of Power Sources 348: 130-137 (30 April 2017)

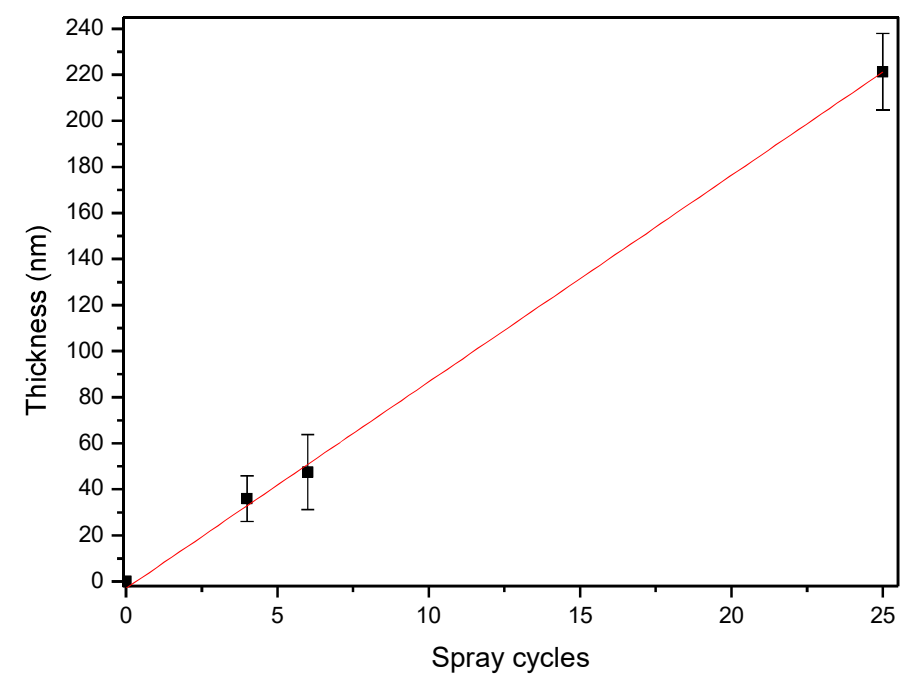

Figure S3: Layer thickness evolution as function of deposition cycles, based on In-Sn-precursor (10 mM, 10\% Sn) deposition with ultrasonic spray deposition on Si native oxide substrates. Thicknesses were measured by SEM after 1 hour anneal in static air at $600^{\circ} \mathrm{C}$. 
E.J. van den Ham et al. - Published in Journal of Power Sources 348: 130-137 (30 April 2017)

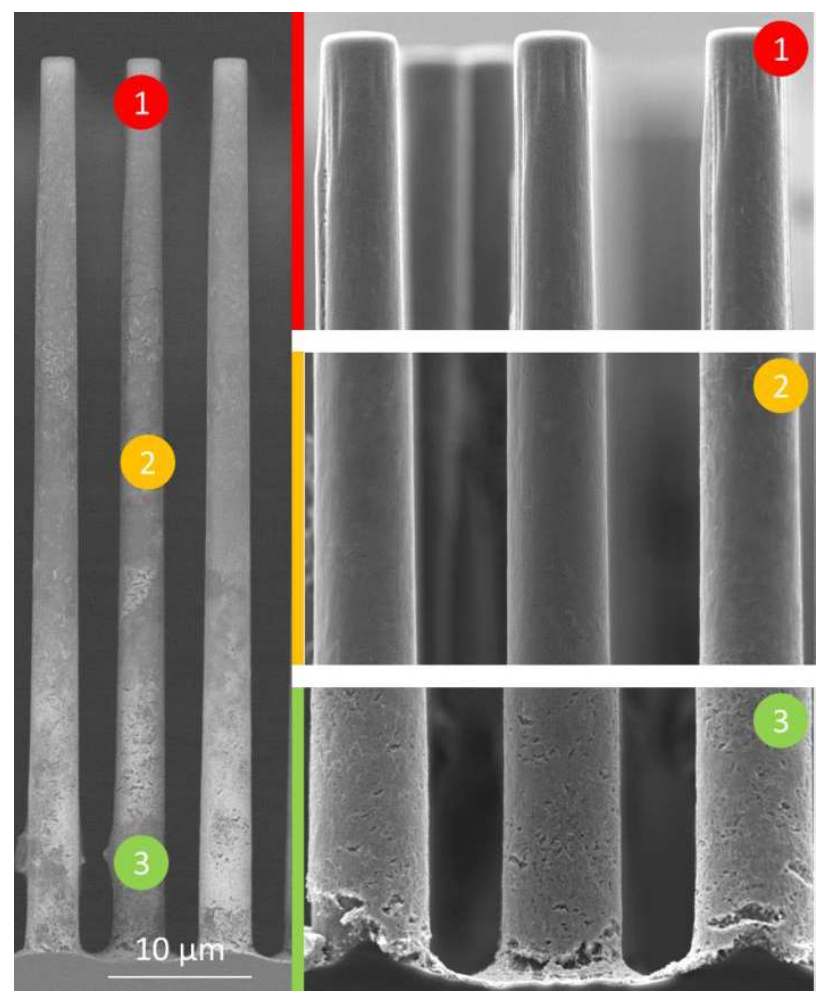

Figure S4: SEM micrograph of ITO film on Si micro-cylinders, as a results of 50 spray deposition cycles with $10 \mathrm{mM}$ ITO citrate precursor, with a deposition temperature of $220^{\circ} \mathrm{C}$. The sample was submitted to a post-deposition anneal at $600^{\circ} \mathrm{C}$ for 1 hour in static air. Artifacts on top of the micro-cylinders are a result of the fabrication process (not related to cleaning or ITO deposition). 
E.J. van den Ham et al. - Published in Journal of Power Sources 348: 130-137 (30 April 2017)

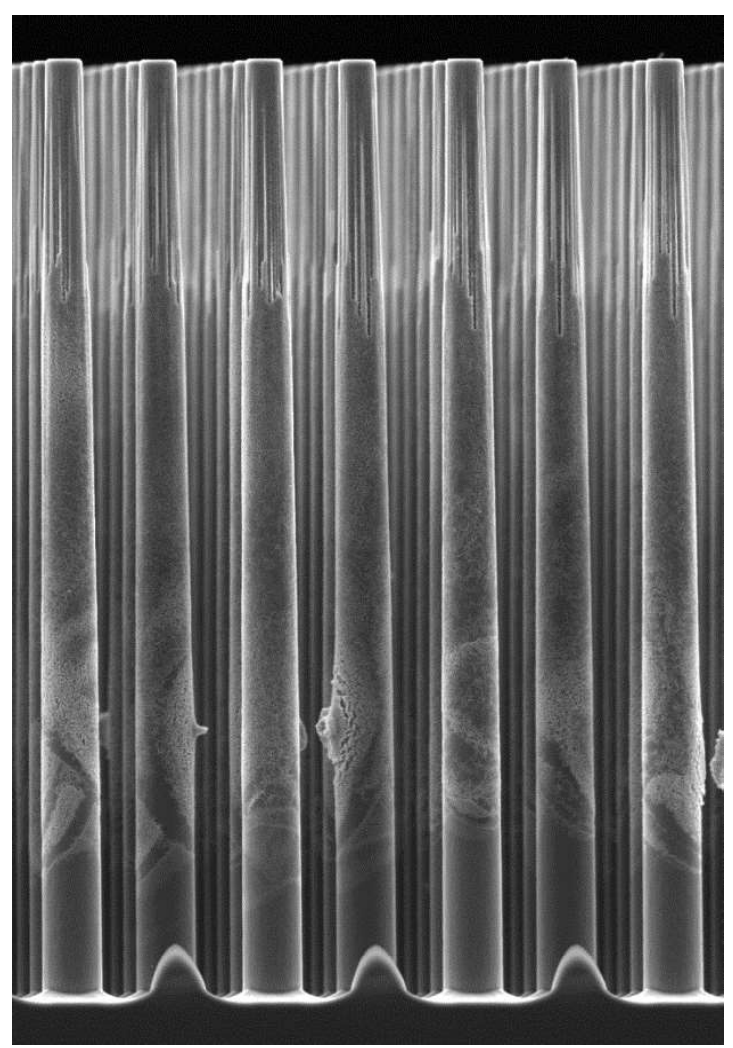

Figure S5: SEM micrograph of ITO films on Si micro-cylinders, as a results of 50 spray deposition cycles with $10 \mathrm{mM}$ ITO citrate precursor at $200^{\circ} \mathrm{C}$. The sample was submitted to $\mathrm{UV} / \mathrm{O}_{3}$ cleaning prior to deposition, and a post-deposition anneal at 600 for 1 hour in dry air (static). 


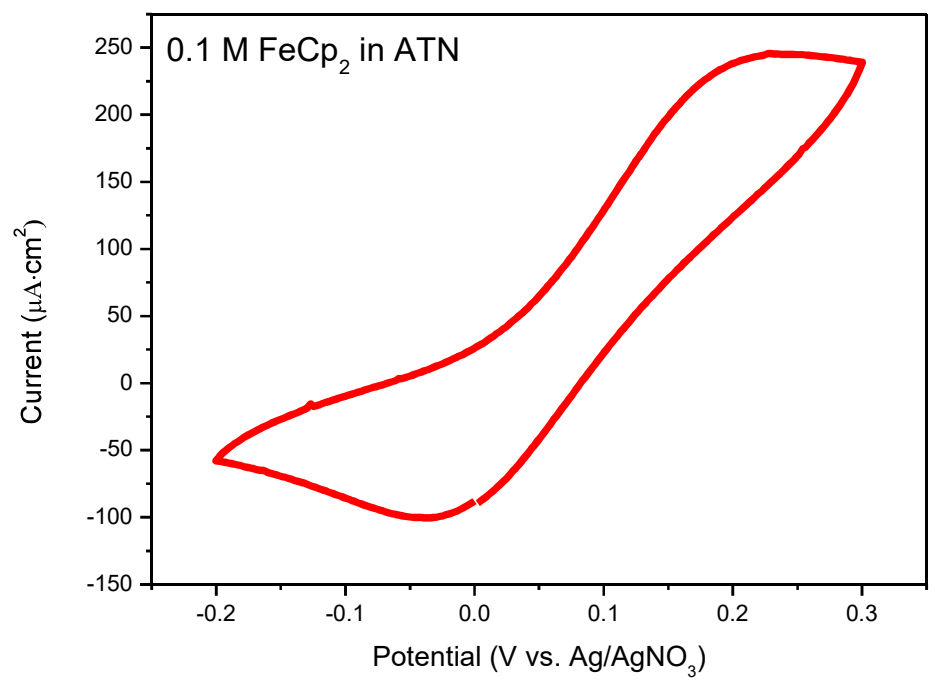

Figure S6: Cyclic voltammogram of a (commercial) sputtered ITO film $(10 \mathrm{mV} / \mathrm{s})$.

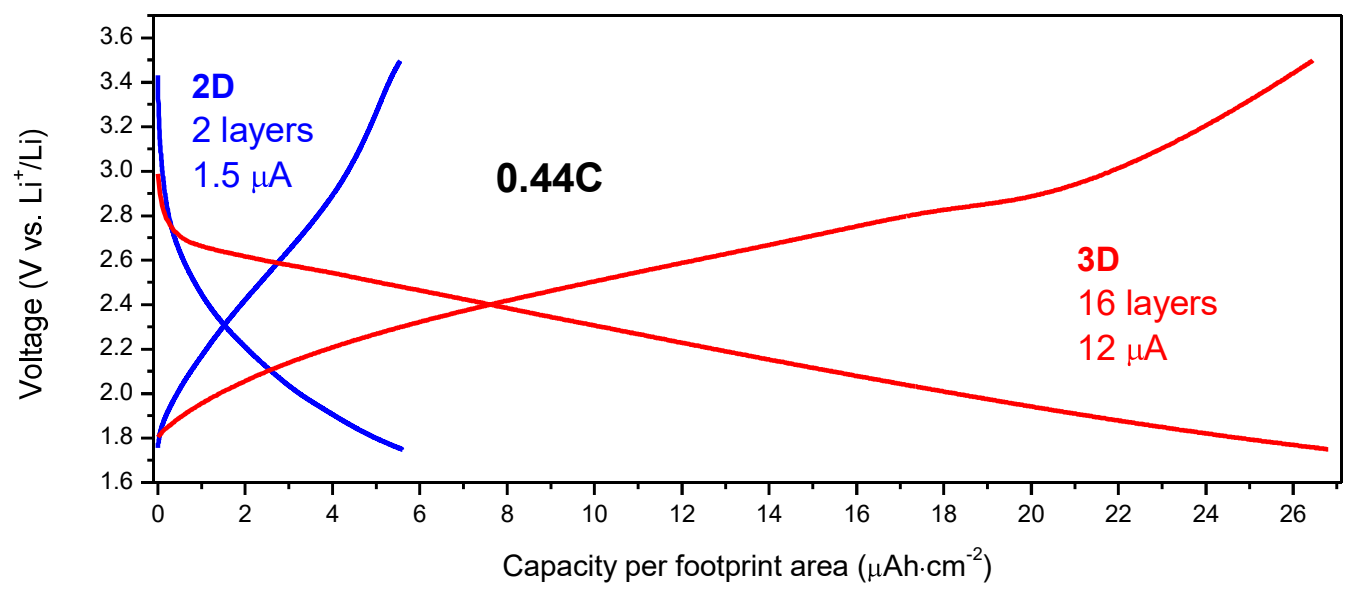

Figure S7: (de)Lithiation results of planar (2D) and 3D $\mathrm{WO}_{3}$ coated ITO on Si micro-cylinders with aspect ratio 10. The planar and 3D samples were coated by 2 / 25 and 16 / 50 deposition cycles of W-precursor / In-Sn-precursor, annealed at $800^{\circ} \mathrm{C}$ (10 minutes) $+400^{\circ} \mathrm{C}$ ( 3 hours) in dry air $+\mathrm{N}_{2}$. Cut-off voltages of 1.75 and $3.5 \mathrm{~V}(\mathrm{vs}$. Li/Li') were chosen, with discharge currents per $\mathrm{cm}^{2}$. Results for cycle 10 (Figure 8) are shown. 
E.J. van den Ham et al. - Published in Journal of Power Sources 348: 130-137 (30 April 2017) 